\title{
Association with Bronchial Carcinoma and Pulmonary Tuberculosis: About 1 Case
}

\author{
Meriem Berkchi*, Leila Herrak, Dalal Zegouch, Leila Achachi, and Moustafa EL Ftouch \\ Department of Pulmonology, Mohammed V University, Morocco
}

Submission: August 27, 2020; Published: November 03, 2020

*Corresponding author: Meriem Berkchi, Department of Pulmonology, Ibn Sina Hospital Faculty of Medicine, Mohammed V University, Rabat, Morocco

Summary

The coexistence of lung cancer and pulmonary tuberculosis is a relatively rare and can be difficult to diagnose. We present the medical observation of a discovery concomitant of these 2 pathologies. This is a 68-year-old patient, a chronic 30 packet smoker weaned 2 years ago, followed for Parkinson's disease under treatment and presented in a picture of dyspnea associated with productive cough bringing back mucopurulent sputum in a feverish context and whose chest x-ray showed total atelectasis of the left lung. A fibroscopy bronchial examination showed a budding stenosis of the left main bronchus and biopsies of the bud were in favor of adenocarcinoma. A chest CT done as part of the assessment of extension having objectified micronodules in tree bud making suspect a possible pulmonary tuberculosis and which has been confirmed by evidence of AFB in the fluid bronchial aspiration. The patient was put on antibacillary treatment and then referred to the service oncology for oncology treatment. The concomitant association between tuberculosis and neopulmonary disease exists with multiple pathophysiological mechanisms and thus complicates the diagnosis and prognosis.

Keywords: Tuberculosis; Dyspnea; Pleuropulmonary; Anthracotic; Adenocarcinoma

Abbreviation: LOH: Loss of Heterozygosity

\section{Introduction}

The relationship between lung cancer and tuberculosis are complex. The combination of these two pathologies in the same patient complicates management and prognosis. In this observation, we report a case of simultaneous discovery of lung cancer and tuberculosis in a context of addiction to tobacco.

\section{Medical Observation}

Mr L.M, 68 years old, chronic tobacco user at the rate of 30 packs year weaned 2 years ago, followed for Parkinson's disease for 1 year under L-DOPA. The patient presented a clinical symptomatology made up of a dyspnea progressive worsening which became stage III of the Mmrc associated with a cough bringing back mucopurulent sputum evolving in a context of fever with night chill and weight loss amounting to $10 \mathrm{~kg}$. The clinical examination found a change in the condition general with a PS of 3 , a fever estimated at $38.5^{\circ} \mathrm{C}$ in the evening and the pleuropulmonary examination objectified a decrease in vesicular murmurs in the depends on the left thoracic hemisphere. The Chest X-ray showed atelectasis of the left lung with a stop image at the left main bronchus (Figure 1).
Chest CT had objectified a process tissue causing bronchial atelectasis left stump, there are also on the right side multiple parenchymal micronodules including some with a tree bud appearance with complete atelectasis of the left lung (Figure 2).

Biologically, there is evidence of a biological inflammatory syndrome, with a CRP 203 and GB 23,700 predominantly PNN, the hemoglobin was correct and the procalcitonin was negative. The bronchial endoscopy performed, objectified to left: a bud completely obstructing the left and right mainstem bronchus aspect second degree inflammatory disease with the presence of anthracotic spots in the lobe superior. Biopsies taken from the bud came back in favor of a bronchopulmonary adenocarcinoma.

According to clinical, biological and above all CT scan, the search for BK was carried out on the bronchial fluid by the method of GeneXpert, having detected the presence of Mycobacterium tuberculosis. The patient was put on antibacillary treatment and referred to an oncology center for prosecution the management of his cancerous disease. 


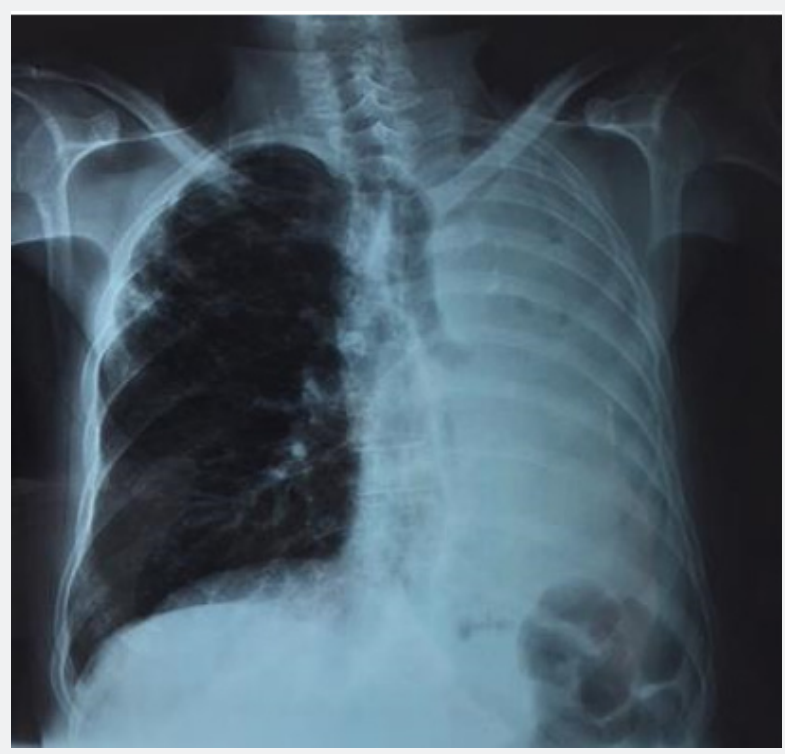

Figure 1: chest x-ray objectifying faces a stop image at the level of the main bronchus left with atelectasis of the left lung.

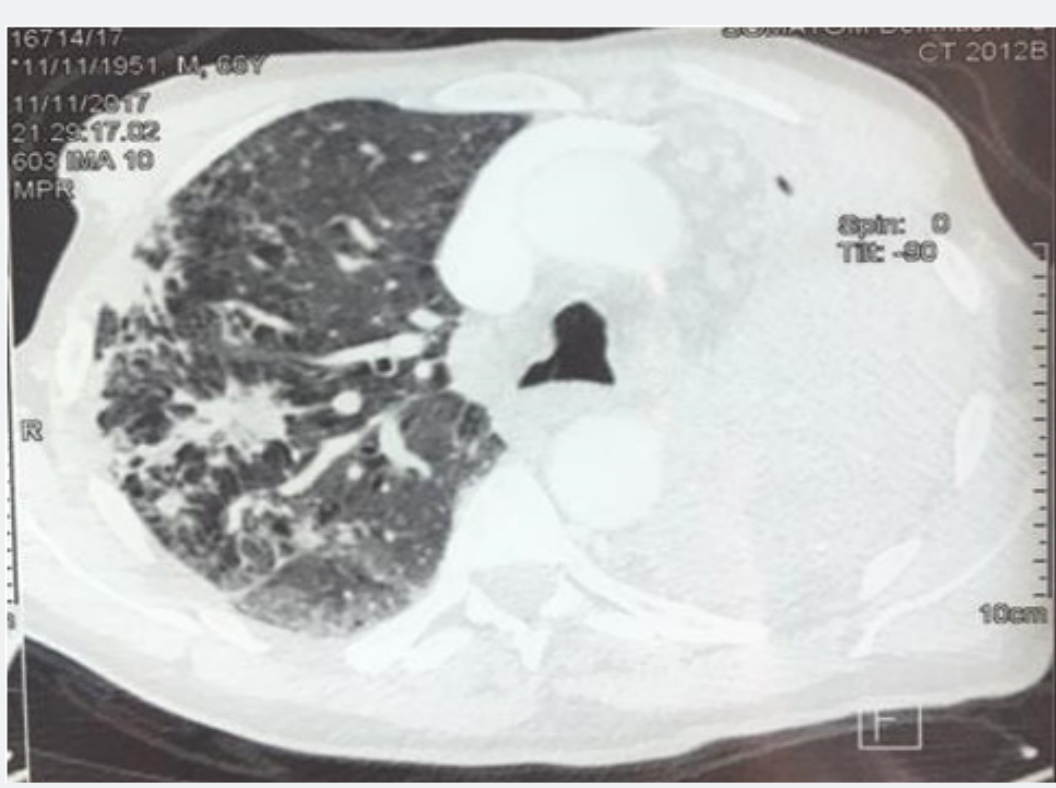

Figure 2: cross section of a CT scan axial thoracic in parenchymal window objectifying a total atelectasis of the left lung and nodular and micronodular lesions of the lobe upper right, some of which have a distribution in bud tree.

\section{Discussion}

The coexistence of lung cancer and active pulmonary tuberculosis is relatively rare. First described in 1810 [1] and since several studies have been interested in the description of this association and from which follows probably a plausible biological mechanism. Reporting a case of pulmonary tuberculosis and bronchial neoplasia discovered in a concomitant in a context of consumption of tobacco.
The association of these 2 pathologies occurs in the majority of cases sequentially with a high risk of developing lung cancer in the first 2 years [2]. It is estimated that 1 to $2 \%$ of bronchial cancers are associated with tuberculosis, while tuberculosis is associated with bronchopulmonary cancer in 1 to $5 \%$ of cases [3]. The simultaneous discovery of these 2 pathologies is relatively rare. Due to the clinical similarity between tuberculosis and neobronchopulmonary disease, the diagnosis of one or the other can go unnoticed in the context where these 2 diseases appear at the 
same time and the diagnosis can unfortunately be made at an advanced stage $[4,5,2]$.

The chest x-ray alone is not sufficient to make the diagnosis of pulmonary tuberculosis, however in our reported case, the presence of total atelectasis of the left lung as well as the history of tobacco consumption guided the diagnosis of bronchopulmonary cancer without, however, suggest tuberculosis and the diagnosis was corrected by thoracic CT, objectifying the appearance of a bud tree and which was confirmed by the demonstration of AFB in the bronchial suction fluid.

Adenocarcinoma has been described as the type most found histologic in subjects with active tuberculosis and has been reported by some authors as a significant association. This histological type was also found in our case [2-6]. Different studies have observed an association coherence between tuberculosis and neo bronchopulmonary disease and therefore several mechanisms incriminated have been explained by various studies. The inflammatory hypothesis was described as providers of neoplasm. Some have reported that activation of tuberculous granuloma is seen following the extension of the neoplasm [7]. Others have reported that the inflammation associated with infections may promote carcinogenesis [8], because certain elements produced by neutrophils activated can bind to DNA inducing a genetic damage and transformation neoplastic [9-10].

According to Song's study [11], the impact of some genetic abnormalities has been described as provider of this association. In this study, it was determined that the subjects, having a tuberculosis associated with cancer, had an abnormal increase in gene expression FHIT compared to those with only cancer and that the loss of heterozygosity ( $\mathrm{LOH})$ of the FHIT gene was statically significant for this association. In our case, the analysis genetics could not be realized. Despite the cumulative effects of tobacco as carcinogen, the relationship between tuberculosis and lung cancer persists even after control smoking.

A meta-analysis [12] corroborated this evidence, showing that there was an increase of 1.78 times the risk of lung cancer in non-smoker patients with tuberculosis. General and local induced immunosuppression by cancer disease accelerates the development of tuberculosis and its expression, as infections may have been the result of a weakened immune system lung cancer [13].

\section{Conclusion}

This observation describes the difficulties of diagnosing the association between tuberculosis and bronchopulmonary cancer, hence the interest of thoracic CT and probably of a systematic search for AFB in an endemic country.

\section{References}

1. Dacosta NA, Kinare SG (1991) Association of lung carcinoma and tuberculosis. J Postgrad Med 37(4): 185-189.

2. Silva DR, Valentini DF, Muller AM, Almeida CP, Dalcin Pde T (2013) Pulmonary tuberculosis and lung cancer: simultaneous and sequential occurrence. J Bras Pneumol 39(4): 484-489.

3. Brenner DR, Mc Lauglin JC, Hung RJ (2011) Previous lung disease and lung cancer risk: a systematic review and meta-analysis. PLoS One 6(3): e17479.

4. Watanabe A, Tokue Y, Takahashi H, Sato K, Nukiwa T, et al. (1999) Management of mycobacteriosis in general hospital without isolation ward for tuberculosis patients. Clinical study on pulmonary tuberculosis associated with lung cancer patients [Article in Japanese] Kekkaku 74(2): 157-162.

5. Singh VK, Chandra S, Kumar S, Pangtey G, Mohan A, et al. (2009) A common medical error: lung cancer misdiagnosed as sputum negative tuberculosis. Asian Pac J Cancer Prev 10(3): 335-338.

6. SK Park, LY Cho, JJ Yang, B Park, SH Chang, et al. (2010) Lung cancer risk and cigarette smoking, lung tuberculosis according to histologic type and gender in a population based case-control study. Lung cancer 68(1): 20-26.

7. Liang HY, Li XL, Yu XS, Guan P, Yin ZH, et al. (2009) Facts and fiction of the relationships between pre-existing tuberculosis and lung cancer risk: a systematic review. Int J Cancer 125(12): 2936-2944.

8. Coussens LM, Werb Z (2002) Inflammation and cancer. Nature 420(6917): 860-867.

9. Lin WW, Karin M (2007) A cytokine-mediated link between innate immunity, inflammation, and cancer. J Clin Invest 117(5): 1175-1183.

10. Rosin MP, Anwar WA, Ward AJ (1994) Inflammation, chromosomal instability, and cancer: the schistosomiasis model. Cancer Research 54(7 Suppl): 1929s-1933s.

11. L Song, W Yan, T Zhao, M Deng, S Song, et al. (2005) Mycobacterium tuberculosis infection and FHIT gene alterations in lung cancer. Cancer letters 219(2): 155-162.

12. Liang HY, Li XL, Yu XS, Guan P, Yin ZH, et al. (2009) Facts and fiction of the relationship between preexisting tuberculosis and lung cancer risk: a systematic review. Int J Cancer 125(12): 2936-2944.

13. Wu CY, Hu HY, Pu CY, Huang N, Shen HC, et al. (2011) Aerodigestive tract, lung and haematological cancers are risk factors for tuberculosis: an 8-year population-based study. Int J Tuberc lung Dis 15(1): 125-130. 
This work is licensed under Creative Commons Attribution 4.0 License

DOI: 10.19080/IJOPRS.2020.04.555643
Your next submission with Juniper Publishers will reach you the below assets

- Quality Editorial service

- Swift Peer Review

- Reprints availability

- E-prints Service

- Manuscript Podcast for convenient understanding

- Global attainment for your research

- Manuscript accessibility in different formats ( Pdf, E-pub, Full Text, Audio)

- Unceasing customer service

Track the below URL for one-step submission https://juniperpublishers.com/online-submission.php 